\title{
Economic burden of chronic bronchitis in the United States: a retrospective case-control study
}

This article was published in the following Dove Press journal: International Journal of Chronic Obstructive Pulmonary Disease I 3 January 20 I |

Number of times this article has been viewed

\section{Christopher M Blanchette' Melissa H Roberts' \\ Hans Petersen' \\ Anand A Dalal ${ }^{2}$ \\ Douglas W Mapel $^{3}$}

'Division of Clinical and Outcomes Research, Lovelace Respiratory Research Institute, Kannapolis, NC, USA; ${ }^{2}$ US Health Outcomes, GlaxoSmithKline, Research Triangle Park, NC, USA; ${ }^{3}$ Lovelace Clinic Foundation, Albuquerque, NM, USA
Correspondence: Christopher M Blanchette

Division of Clinical and Outcomes Research, Lovelace Respiratory Research Institute, II 5 West Avenue, Kannapolis, NC 2808I, USA

Tel +l 7049380530

Fax +I 7046257170

Email cblanchette@Irri.org
Background: Chronic bronchitis (CB) is often misdiagnosed or diagnosed at a later stage of chronic obstructive pulmonary disease (COPD). We examined how this later diagnosis may impact health care costs and utilization during the 12 months prior to and 24 months post initial CB diagnosis.

Methods: This retrospective case-control analysis used claims data from a large US database from July 1, 2003 through June 30, 2007. Patients with CB aged 40 years and older were propensity matched $(\mathrm{N}=11,674)$ to patients without evidence of COPD or asthma by demographics, CB diagnosis quarter/year, and comorbidities. Group differences were assessed using Student's $t$-test and Pearson chi-square test statistics.

Results: Six months prediagnosis, CB patients had higher frequencies of any hospitalization $(9.6 \%, 6.7 \% ; P<0.05)$, emergency department/urgent care visits $(13.3 \%, 6.7 \% ; P<0.05)$, and prescriptions $(97.3 \%, 94.1 \% ; P<0.05)$. Six months postdiagnosis, CB patients had 5.6 times more hospitalizations $(P<0.05)$ and 3.1 times more emergency department/urgent care visits $(P<0.05)$ compared with controls. Mean total costs (US\$) for CB patients 12 months prediagnosis were significantly higher than controls (months $12-7$ : $\$ 4212, \$ 3826 ; P<0.05$; months 6-1: $\$ 5289, \$ 4285 ; P<0.05)$. CB patients had higher mean total costs $(\$ 8919$; $P<0.05) 6$ months postdiagnosis. Costs remained \$2429 higher for CB patients 19-24 months postdiagnosis $(P<0.05)$.

Conclusion: Health care costs and utilization among CB patients are increased both prior to diagnosis and during the 2 years postdiagnosis. This study suggests that not accurately diagnosing $\mathrm{CB}$ early has a substantial impact on health care costs, and that the economic burden for $\mathrm{CB}$ patients remains elevated even after adjustment for comorbidities associated with COPD.

Keywords: chronic bronchitis, burden, economic, chronic obstructive pulmonary disease

\section{Introduction}

Chronic bronchitis (CB), an inflammatory condition that affects the central bronchi, is one of two main lung diseases by which patients with chronic obstructive pulmonary disease (COPD) are characterized. Excessive mucus secretion differentiates it from the second, emphysema, which is characterized by permanent enlargement of lung airways and destruction of the walls of the alveoli, making breathing difficult. ${ }^{1}$ Other symptoms of CB related to lung inflammation and heavy mucus production include cough, production of sputum, and dyspnea. ${ }^{1}$ In 2008, more than 9.8 million Americans reported having a $\mathrm{CB}$ diagnosis. ${ }^{2}$ While many patients with COPD may suffer from both conditions, the courses of the diseases and response to treatment are frequently different; separate studies of outcomes between the two could assist in optimizing care for these patients. 
Estimated annual expenditures for CB treatment total US\$11.7 billion, with hospitalizations accounting for US\$ 6 billion of the total costs. ${ }^{3}$ There are limited studies that examine the costs associated with $\mathrm{CB}$, but research has shown that hospitalizations for acute $\mathrm{CB}$ exacerbations accounted for $46 \%-90 \%$ of the costs associated with treatment. ${ }^{4}$ The diminished quality of life experienced by COPD patients is well documented and suggests that earlier detection, treatment, and reduction of exacerbations may have a substantial economic and psychosocial impact on patients. $^{5-13}$

The chronic cough and sputum production associated with $\mathrm{CB}$ often predates the development of airflow limitation. ${ }^{14}$ The GOLD (Global Initiative for Chronic Obstructive Lung Disease) guidelines for diagnosis and treatment of COPD recommend early identification of patients with symptoms of $\mathrm{CB}$ in order to begin intervention at the earliest stage of COPD. ${ }^{14}$ Unfortunately, CB symptoms may be dismissed by patients as "smoker's cough", or physicians may misdiagnose $\mathrm{CB}$ as acute bronchitis or asthma. ${ }^{15,16}$ Once CB is diagnosed and treatment has commenced, many patients have progressed into more severe COPD stages, resulting in higher consumption of health care resources and increased complexity in clinical management.

Prior research demonstrated higher utilization rates of health care resources for COPD patients when compared with a control population during the 12 months preceding initial COPD diagnosis. ${ }^{17}$ Utilization trends indicated an increasing use of resources in terms of medical services and pharmacy prescriptions up to the COPD diagnosis, particularly in the final month before diagnosis. ${ }^{17}$ In addition, total costs for COPD patients have been shown to be higher up to 2 years prior to diagnosis. ${ }^{18}$ To determine if these trends were apparent for the subset of COPD patients diagnosed with $\mathrm{CB}$, we examined health care utilization and costs for 12 months prior to CB diagnosis and 24 months post diagnosis.

\section{Data and methods Study design and data source}

This case-control analysis used data from the PharMetrics Integrated Database, which contains continuously updated information from enrollment files and facility, professional services, and outpatient pharmacy claims from more than 90 participating US health plans, representing more than 55 million patients. The data include dates of service and International Classification of Diseases, 9th Revision, Clinical Modification (ICD-9-CM) diagnosis codes, participating plan payment and billed charge information. The dataset is deidentified and Health Insurance Portability and Accountability Act (HIPAA) compliant.

\section{Sample}

$\mathrm{CB}$ and control cohorts were selected using medical claims data for services provided between July 1, 2003 and June 30, 2007. The CB cohort consisted of patients with an initial primary or secondary diagnosis claim of CB (ICD-9-CM codes 491.xx), considered the index event, during the observation period described above. All study patients were required to be aged 40 or older and to have had continuous enrollment in a health plan for at least 12 months prior to the initial diagnosis (index date). Thus the earliest index date was July 1, 2004. In addition to the preindex health plan enrollment period, subjects were also required to remain enrolled in a health plan for a minimum of 1 year, to have at least one prescription claim in both the pre- and postindex observational time periods (to provide evidence of pharmaceutical insurance coverage) and to have no prior claims for any COPD-related outpatient visit.

Patients in the potential control cohort had at least 36 months of continuous enrollment between July 1, 2003 and June 30, 2007. Index dates were randomly assigned to control cohort subjects following the first 12 months of continuous enrollment. Patients in the potential control cohort had no evidence of bronchitis, chronic bronchitis, emphysema, asthma, or unspecified COPD (ICD-9-CM codes 490.xx, 491.xx, 492.xx, 493.xx, 496.xx) during the 12 months prior to the randomly assigned index date, and also had to have at least one medical services claim and one prescription claim pre- and postindex date. Patients with serious lung conditions other than COPD or asthma were excluded from both cohorts. ${ }^{19}$ The likelihood of a CB diagnosis was calculated by a logistic regression that controlled for demographics (age, sex, and geographic region), quarter and year of index date, and comorbidities (Table 1). CB patients were propensity matched one-to-one to control subjects using the greedy match algorithm, a method that derives matched samples using nearest available pair matching. ${ }^{20,21} \mathrm{CB}$ cases were matched to controls according to age, geographic region, quarter of year of index date, and selected comorbidities to reduce selection bias. Comorbid conditions were identified based on the classifications by Elixhauser et $\mathrm{al}^{22}$ sleep apnea and heart disease (rheumatic heart failure, hypertensive heart disease, ischemic heart disease, and unspecified cardiovascular disease) were also included. 
Table I Case patients and control subject characteristics before and after propensity matching

\begin{tabular}{|c|c|c|c|c|c|c|c|c|}
\hline \multirow[t]{3}{*}{ Characteristic } & \multicolumn{4}{|c|}{ Pre-matching } & \multicolumn{4}{|c|}{ Post-matching } \\
\hline & \multicolumn{2}{|c|}{ Cases } & \multicolumn{2}{|c|}{ Controls } & \multicolumn{2}{|c|}{ Cases } & \multicolumn{2}{|c|}{ Controls } \\
\hline & $\mathbf{N}(\%)$ & & $\mathbf{N}(\%)$ & & N (\%) & & $\mathbf{N}(\%)$ & \\
\hline Number of patients & 11937 & & 280264 & & 11674 & & 11674 & \\
\hline Age, yrs (mean, SD) & 61.8 & 12.2 & 57.2 & 10.9 & 61.5 & 12.1 & 61.8 & 12.1 \\
\hline \multicolumn{9}{|l|}{ Sex } \\
\hline Male & 4944 & $(41.4 \%)$ & 119264 & $(42.6 \%)$ & 4832 & (4I.4\%) & 5017 & $(43.0 \%)^{b}$ \\
\hline Female & 6993 & $(58.6 \%)$ & 161000 & $(57.4 \%)$ & 6842 & $(58.6 \%)$ & 6657 & $(57.0 \%)^{b}$ \\
\hline \multicolumn{9}{|l|}{ Region } \\
\hline Midwest & 2093 & $(17.5 \%)$ & 77533 & $(27.7 \%)$ & 2082 & $(17.8 \%)$ & 2010 & (17.2\%) \\
\hline Northeast & 4515 & $(37.8 \%)$ & 67901 & $(24.2 \%)$ & 4334 & (37.1\%) & 4308 & (36.9\%) \\
\hline South & 3315 & $(27.8 \%)$ & 71932 & $(25.7 \%)$ & 3269 & $(28.0 \%)$ & 3301 & $(28.3 \%)$ \\
\hline West & 2014 & $(16.9 \%)$ & 62898 & $(22.4 \%)$ & 1989 & $(17.0 \%)$ & 2055 & $(17.6 \%)$ \\
\hline \multicolumn{9}{|l|}{ Quarter and year of the index date } \\
\hline Q3-2004 & 1210 & $(10.1 \%)$ & 48236 & $(17.2 \%)$ & $120 \mid$ & $(10.3 \%)$ & 1227 & $(10.5 \%)$ \\
\hline Q4-2004 & 1677 & $(14.0 \%)$ & 50105 & $(17.9 \%)$ & 1657 & $(14.2 \%)$ & 1664 & $(14.3 \%)$ \\
\hline QI-2005 & 2337 & $(19.6 \%)$ & 50674 & $(18.1 \%)$ & 2288 & $(19.6 \%)$ & 2254 & (19.3\%) \\
\hline Q2-2005 & 1472 & $(12.3 \%)$ & 26573 & $(9.5 \%)$ & 1438 & $(12.3 \%)$ & 1440 & $(12.3 \%)$ \\
\hline Q3-2005 & 1140 & $(9.6 \%)$ & 27554 & $(9.8 \%)^{\mathrm{a}}$ & 1113 & $(9.5 \%)$ & 1144 & $(9.8 \%)$ \\
\hline Q4-2005 & 1499 & $(12.6 \%)$ & 27028 & $(9.6 \%)$ & 1465 & $(12.5 \%)$ & 1474 & $(12.6 \%)$ \\
\hline Q1-2006 & 1588 & $(13.3 \%)$ & 25707 & $(9.2 \%)$ & 1524 & $(13.1 \%)$ & 1529 & $(13.1 \%)$ \\
\hline Q2-2006 & 1014 & $(8.5 \%)$ & 24387 & $(8.7 \%)^{\mathrm{a}}$ & 988 & $(8.5 \%)$ & 942 & $(8.1 \%)$ \\
\hline \multicolumn{9}{|l|}{ Comorbid conditions } \\
\hline Asthma* & 2722 & $(22.8 \%)$ & & & 2660 & $(22.8 \%)$ & & \\
\hline Alcohol abuse & 152 & $(1.3 \%)$ & 1498 & $(0.5 \%)$ & 139 & $(1.2 \%)$ & 135 & $(1.2 \%)$ \\
\hline Blood loss anemia & 121 & $(1.0 \%)$ & 1406 & $(0.5 \%)$ & 108 & $(0.9 \%)$ & 96 & $(0.8 \%)$ \\
\hline Cardiac arrythmia & 1348 & (11.3\%) & 14709 & $(5.2 \%)$ & 1210 & $(10.4 \%)$ & 1243 & $(10.6 \%)$ \\
\hline Congestive heart failure & 1083 & $(9.1 \%)$ & 4979 & $(1.8 \%)$ & 856 & (7.3\%) & 785 & $(6.7 \%)$ \\
\hline Coagulopathy & 245 & $(2.1 \%)$ & 2457 & $(0.9 \%)$ & 217 & $(1.9 \%)$ & 204 & $(1.7 \%)$ \\
\hline Cardiovascular disease & 185 & $(1.5 \%)$ & 2041 & $(0.7 \%)$ & 168 & $(1.4 \%)$ & 186 & (1.6\%) \\
\hline Deficiency anemias & 1005 & $(8.4 \%)$ & 14636 & $(5.2 \%)$ & 921 & $(7.9 \%)$ & 949 & $(8.1 \%)$ \\
\hline Depression & 970 & $(8.1 \%)$ & 16865 & $(6.0 \%)$ & 928 & $(7.9 \%)$ & 929 & $(8.0 \%)$ \\
\hline Diabetes & 2380 & $(19.9 \%)$ & $37 \mid 44$ & $(13.3 \%)$ & 2247 & (19.2\%) & 2265 & (19.4\%) \\
\hline Fluid and electrolyte disorders & 792 & $(6.6 \%)$ & 7268 & $(2.6 \%)$ & 685 & $(5.9 \%)$ & 676 & $(5.8 \%)$ \\
\hline Hypertension (complicated) & 600 & $(5.0 \%)$ & 5605 & $(2.0 \%)$ & 531 & $(4.5 \%)$ & 531 & $(4.5 \%)$ \\
\hline Hypertension (uncomplicated) & 5867 & $(49.1 \%)$ & 105482 & $(37.6 \%)$ & 5644 & $(48.3 \%)$ & 5671 & $(48.6 \%)$ \\
\hline Hypothyroidism & 1238 & $(10.4 \%)$ & 26781 & $(9.6 \%)$ & 1199 & $(10.3 \%)$ & 1245 & $(10.7 \%)$ \\
\hline Ischemic heart disease & 2411 & $(20.2 \%)$ & 25481 & (9.1\%) & 2215 & $(19.0 \%)$ & 2293 & $(19.6 \%)$ \\
\hline Liver disease & 235 & $(2.0 \%)$ & 3278 & $(1.2 \%)$ & 213 & $(1.8 \%)$ & 212 & $(1.8 \%)$ \\
\hline Obesity & 543 & $(4.5 \%)$ & 7678 & $(2.7 \%)$ & 500 & $(4.3 \%)$ & 556 & $(4.8 \%)$ \\
\hline Other neurological disorders & 421 & $(3.5 \%)$ & 5777 & $(2.1 \%)$ & 381 & $(3.3 \%)$ & 383 & $(3.3 \%)$ \\
\hline Paralysis & 89 & $(0.7 \%)$ & 906 & $(0.3 \%)$ & 77 & $(0.7 \%)$ & 87 & $(0.7 \%)$ \\
\hline Peripheral vascular disorders & 950 & $(8.0 \%)$ & 3711 & (1.3\%) & 838 & $(7.2 \%)$ & 837 & $(7.2 \%)$ \\
\hline Psychoses & 706 & $(5.9 \%)$ & 10368 & $(3.7 \%)$ & 670 & $(5.7 \%)$ & 677 & $(5.8 \%)$ \\
\hline Pulmonary circulation disorders & 139 & $(1.2 \%)$ & 560 & $(0.2 \%)$ & 92 & $(0.8 \%)$ & 88 & $(0.8 \%)$ \\
\hline Renal failure & 357 & $(3.0 \%)$ & 3209 & (I.1\%) & 296 & $(2.5 \%)$ & 277 & $(2.4 \%)$ \\
\hline Rheumatic heart failure & 7 & $(0.1 \%)$ & 37 & $(0.0 \%)$ & 4 & $(0.0 \%)$ & 4 & $(0.0 \%)$ \\
\hline $\begin{array}{l}\text { Rheumatoid arthritis/collagen } \\
\text { vascular }\end{array}$ & 525 & $(4.4 \%)$ & 8154 & $(2.9 \%)$ & 503 & $(4.3 \%)$ & 522 & $(4.5 \%)$ \\
\hline Obstructive sleep apnea & 628 & $(5.3 \%)$ & 7919 & $(2.8 \%)$ & 580 & $(5.0 \%)$ & 580 & $(5.0 \%)$ \\
\hline Peptic ulcer excluding & 120 & $(1.0 \%)$ & 1486 & $(0.5 \%)$ & 115 & $(1.0 \%)$ & 112 & $(1.0 \%)$ \\
\hline bleeding & & & & & & & & \\
\hline Valvular disease & 1032 & $(8.6 \%)$ & 11913 & $(4.3 \%)$ & 924 & $(7.9 \%)$ & 972 & $(8.3 \%)$ \\
\hline Weight loss & 51 & $(0.4 \%)$ & 306 & $(0.1 \%)$ & 37 & $(0.3 \%)$ & 41 & $(0.4 \%)$ \\
\hline
\end{tabular}

Notes: Propensity score calculated as probability of chronic bronchitis diagnosis using a logistic regression controlling for demographics (age, sex, region), quarter and year of the index date, and comorbid conditions listed. *Asthma was specifically excluded in the control population; ${ }^{2}$ No signficant difference between chronic bronchitis (CB) cohort and control cohort at level of 0.05 ; 'Signficant difference between CB cohort and control cohort at level of 0.05 . Q1, July I to Sept 30, Q2, Oct I to Dec 31 , Q3, Jan I to March 3I, Q4, April I to June 30.

Abbreviation: SD, standard deviation. 


\section{Measures}

Utilization and costs due to all causes in both the pre- and postindex periods were categorized by inpatient hospitalization (IP), emergency department/urgent care (ED/UC), outpatient visits (OP), and pharmacy fills. Utilization and costs occurring on the index date were included in the first 6-month period postindex. We defined costs as the amount paid by the health plan; costs paid by other sources were not included. Costs for IP, OP, and ED/UC were aggregated as medical services costs. Pharmacy costs were kept separate; total costs were the sum of medical services and pharmacy costs. Each category for both cohorts was analyzed for six time periods of 6 months each: two in the preindex period and four during the postindex period.

\section{Analysis}

Descriptive analysis was used for all demographic, patient comorbidity, and outcome variables. Continuous variables were reported as means, standard deviations, and medians. Binary and categorical variables were reported as counts and percentages.

Means and frequencies for utilization and costs were calculated and compared for all outcome categories in both the pre- and postindex periods. Covariate adjustment was incorporated through the use of a propensity score matching technique as previously described. The Student's $t$-test and Wilcoxon rank-sum test was used for continuous variables and the Pearson chi-square test for binary use variables. All statistical tests were two-sided with a 0.05 level of significance. Analyses were conducted with SAS software (version 9.1.3 for Windows; SAS Institute, Cary, NC).

\section{Results}

There were initially 182,169 patients who had a COPD diagnosis at any time; after selection criteria were applied, 11,937 patients met criteria for the $\mathrm{CB}$ cohort. A $10 \%$ random sample of possible control subjects with 3 or more years of continuous enrollment was selected, of whom 282,078 met the control cohort selection criteria. These patients were randomly reduced to a pool of 65,654 control patients. Propensity score matching was used to match CB patients to control patients on a one-to-one basis, resulting in two cohorts of 11,674 each.

Prior to matching, the two cohorts exhibited significant differences in all matching characteristics with the exception of two of the index date quarter variables (Table 1). After matching, the CB patient cohort and control patient cohort exhibited a significant difference only in the percentage of each population that was male $(\mathrm{CB}=41.4 \%$, control $=43.0 \%$; $P=0.0142)$. The cohorts were similar with respect to comorbidities, geographic region, mean age, and quarter in which the index date occurred.

After matching, the mean age of patients in the $\mathrm{CB}$ cohort was 61.5 years; for the controls, 61.8 years. Patients were predominantly from the Northeast (37\%) and female (57.8\%). The most prevalent comorbidities in each cohort were: uncomplicated hypertension (48.5\%), diabetes (19.3\%), ischemic heart disease (19.3\%), arrhythmia (10.5\%), and hypothyroidism (10.5\%), shown in Table 1. Among the CB cohort, $22.8 \%$ had a history of asthma in addition to their $\mathrm{CB}$ diagnosis.

There was a decrease in the number of patients with continuous enrollment beginning 13 months after the index date. Approximately $23 \%$ of the CB patients were lost to follow-up during months $13-18$, and another $25 \%$ in the 19-24 month period after the index date. For the final 6-month observation period (months 19-24), there were 6128 CB patients and 6203 control patients.

As shown in Table 2 and Figure 1, from 1 year and up to 6 months prior to the $\mathrm{CB}$ diagnosis there were no differences between the cohorts with respect to the percentage of patients having any IP visit; however, the CB cohort had a higher percentage having any $\mathrm{ED} / \mathrm{UC}$ visit $(9.5 \%, 6.4 \% ; P<0.05)$, and any pharmacy use $(93.4 \%, 91.5 \% ; P<0.05)$, while having a lower percentage with any OP visit $(90.5 \%, 92.9 \%$; $P<0.05)$. In the next 6 months, which was the 6 months immediately prior to diagnosis, patients in the $\mathrm{CB}$ cohort, compared with the control cohort, had a higher percentage having any IP visit $(9.6 \%, 6.7 \% ; P<0.05)$, and again, higher percentages for any $\mathrm{ED} / \mathrm{UC}$ visit $(13.3 \%, 6.7 \% ; P<0.05)$, and any pharmacy prescription $(97.3 \%, 94.1 \% ; P<0.05)$. Percentages of patients having any OP visit were identical for the two cohorts during the 6 months immediately prior to $\mathrm{CB}$ diagnosis.

During the first 6 months postindex (Figure 1), patients in the $\mathrm{CB}$ cohort had 5.6 times more IP visits $(30.4 \%, 5.4 \%$; $P<0.05)$ and 3.1 times more $\mathrm{ED} / \mathrm{UC}$ visits $(20.7 \%, 6.6 \%$; $P<0.05$ ). To a lesser degree, OP visits and pharmacy use were also higher for the $\mathrm{CB}$ cohort. Utilization rates remained higher for the $\mathrm{CB}$ cohort during all four of the 6-month periods postindex, but beginning in the second 6-month postindex period, utilization rates in the $\mathrm{CB}$ cohort declined from the highs reached in the first postindex period and remained fairly stable for the remaining observation periods. The control cohort's utilization rates declined slightly in each of the four postindex periods. Mean number of events 
Table 2 Chronic bronchitis patients and control subjects with any health care events

\begin{tabular}{|c|c|c|c|c|c|c|}
\hline \multirow[t]{3}{*}{ Subjects w/any utilization } & \multirow{2}{*}{\multicolumn{2}{|c|}{$\begin{array}{l}\text { Preindex } \\
\text { Months prior to index }\end{array}$}} & \multicolumn{4}{|c|}{ Postindex } \\
\hline & & & \multicolumn{4}{|c|}{ Months after index } \\
\hline & $7-12 *$ & $1-6$ & $1-6$ & $7-12$ & $13-18 * *$ & 19-24 \\
\hline \multicolumn{7}{|l|}{ Hospitalization (IP) } \\
\hline Chronic bronchitis & $6.1 \%$ & $9.6 \%$ & $30.4 \%$ & $10.5 \%$ & $11.0 \%$ & $10.4 \%$ \\
\hline Control & $6.2 \%$ & $6.7 \%$ & $5.4 \%$ & $6.1 \%$ & $5.2 \%$ & $5.7 \%$ \\
\hline \multicolumn{7}{|l|}{ ED/UC visit } \\
\hline Chronic bronchitis & $9.5 \%$ & $13.3 \%$ & $20.7 \%$ & $12.2 \%$ & $12.0 \%$ & $12.3 \%$ \\
\hline Control & $6.4 \%$ & $6.7 \%$ & $6.6 \%$ & $6.8 \%$ & $6.6 \%$ & $6.5 \%$ \\
\hline \multicolumn{7}{|l|}{ Outpatient visit (OP) } \\
\hline Chronic bronchitis & $90.5 \%$ & $93.8 \%$ & $99.7 \%$ & $95.2 \%$ & $94.7 \%$ & $94.2 \%$ \\
\hline Control & $92.9 \%$ & $93.8 \%$ & $94.0 \%$ & $93.7 \%$ & $91.7 \%$ & $91.3 \%$ \\
\hline \multicolumn{7}{|l|}{ Pharmacy use } \\
\hline Chronic bronchitis & $93.4 \%$ & $97.3 \%$ & $99.0 \%$ & $95.2 \%$ & $92.7 \%$ & $91.0 \%$ \\
\hline Control & $91.5 \%$ & $94.1 \%$ & $93.7 \%$ & $92.5 \%$ & $87.7 \%$ & $85.4 \%$ \\
\hline
\end{tabular}

Notes: All percentages were significantly different at a 0.05 level using a chi-square test except for IP visits in pre-index months $12-7$ and OP visits in pre-index months 6-1.

$* \mathrm{~N}=1 \mathrm{I} 674 \mathrm{CB}$ and controls months I2-I preindex and months I-I2 postindex; **N = 9009 CB, 9305 controls months I3-I8 postindex; $\mathrm{N}=6 \mathrm{I} 28 \mathrm{CB}, \mathrm{N}=6203$ controls months 19-24 postindex.

were higher for the $\mathrm{CB}$ cohort in all time periods, pre- and postindex, compared with the control cohort except for mean $\mathrm{OP}$ visits in the 6-month period immediately preceding the CB diagnosis (Table 3, Figure 2).

Mean total costs (US\$) for the CB cohort during both preindex periods were significantly higher than for the control cohort (months 12-7: \$4212, \$3826; $P<0.05$; months 6-1: \$5289, \$4285; $P<0.05)$. Component costs were also higher, with the exception that there was no difference in medical services costs during the initial 6 months prior to diagnosis (Table 4). CB patients had higher mean total costs $(\$ 8919 ; P<0.05)$ in the 6 months postdiagnosis. Costs for both groups then decreased (Figure 3 ) but for CB patients remained $\$ 2429$ higher than for control patients 19-24 months postdiagnosis $(P<0.05)$. Median costs were all significantly higher for the $\mathrm{CB}$ cohort (Table 5).
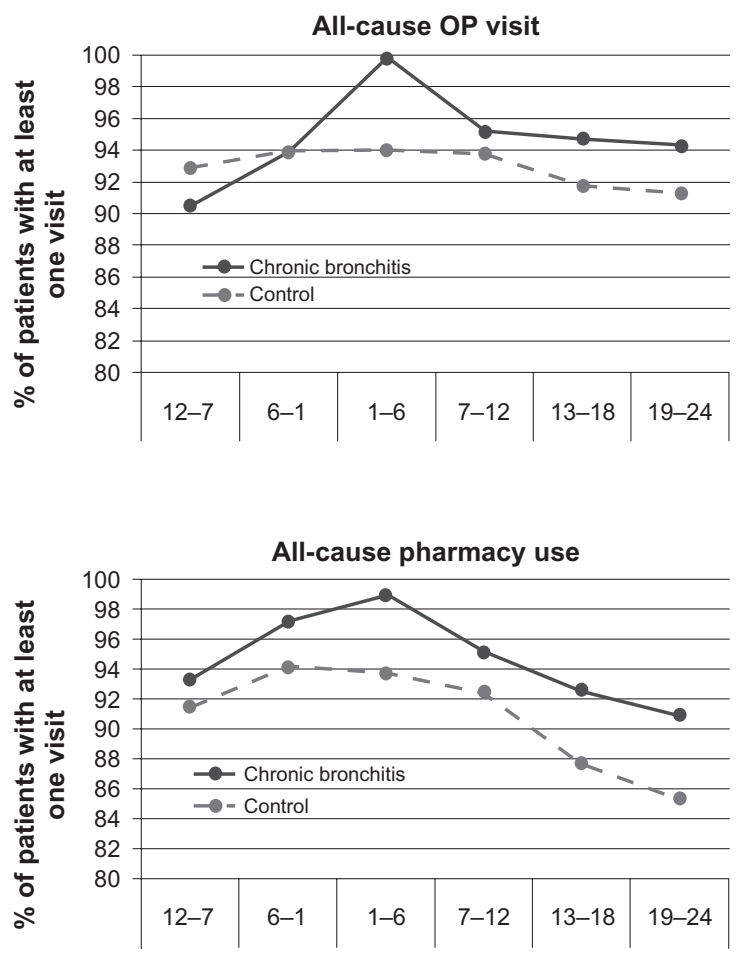

Figure I Incidence of any utilization for all-cause health care events.

Abbreviations: ED/UC, emergency department/urgent care; IP, inpatient hospitalization; OP, outpatient visits. 
Table 3 Total and mean events for chronic bronchitis and control populations

\begin{tabular}{|c|c|c|c|c|c|c|}
\hline & \multicolumn{2}{|c|}{ Preindex } & \multicolumn{4}{|c|}{ Postindex } \\
\hline & \multicolumn{2}{|c|}{ Months prior to index } & \multicolumn{4}{|c|}{ Months after index } \\
\hline & $7-12 *$ & $1-6$ & $1-6$ & $7-12$ & $13-18 * *$ & $19-24$ \\
\hline \multicolumn{7}{|l|}{ Total events } \\
\hline \multicolumn{7}{|l|}{ IP } \\
\hline Chronic bronchitis & 873 & $\mathrm{I}, 378$ & 4,687 & $\mathrm{I}, 633$ & 1,333 & 866 \\
\hline Control & 900 & 973 & 759 & 885 & 593 & 466 \\
\hline \multicolumn{7}{|l|}{ ED/UC visit } \\
\hline Chronic bronchitis & 1,502 & 2,156 & 3,552 & 2,154 & $\mathrm{I}, 595$ & $\mathrm{I}, 078$ \\
\hline Control & 962 & 1,005 & 968 & 1,048 & 767 & 538 \\
\hline \multicolumn{7}{|l|}{$O P$} \\
\hline Chronic bronchitis & 99,773 & 110,543 & 167,877 & $|29,53|$ & 99,122 & 64,805 \\
\hline Control & 92,485 & 97,590 & 94,172 & 94,695 & 72,450 & 48,416 \\
\hline \multicolumn{7}{|l|}{ Pharmacy use } \\
\hline Chronic bronchitis & 220,580 & 237,961 & 288,189 & 256,939 & 192,569 & 126,730 \\
\hline Control & 148,984 & 155,404 & $|56,90|$ & 157,332 & 120,687 & 80,716 \\
\hline \multicolumn{7}{|l|}{ Mean events } \\
\hline \multicolumn{7}{|l|}{ IP } \\
\hline Chronic bronchitis & 0.07 & 0.12 & 0.40 & 0.14 & 0.15 & 0.14 \\
\hline Control & 0.08 & 0.08 & 0.07 & 0.08 & 0.06 & 0.08 \\
\hline \multicolumn{7}{|l|}{ ED/UC visit } \\
\hline Chronic bronchitis & 0.13 & 0.18 & 0.30 & 0.18 & 0.18 & 0.18 \\
\hline Control & 0.08 & 0.09 & 0.08 & 0.09 & 0.08 & 0.09 \\
\hline \multicolumn{7}{|l|}{$O P$} \\
\hline Chronic bronchitis & 8.55 & 9.47 & 14.38 & 11.10 & 11.00 & 10.58 \\
\hline Control & 7.92 & 8.36 & 8.07 & 8.11 & 7.79 & 7.81 \\
\hline \multicolumn{7}{|l|}{ Pharmacy use } \\
\hline Chronic bronchitis & 18.90 & 20.38 & 24.69 & 22.01 & 21.38 & 20.68 \\
\hline Control & 12.76 & $|3.3|$ & 13.44 & 13.48 & 12.97 & $13.0 \mid$ \\
\hline
\end{tabular}

Notes: Numbers of events were significantly different at a 0.05 level using a Wilcoxon Rank Sum test except for IP visits in preindex months I2-7.

$* N=11674 \mathrm{CB}$ and controls months I2-I preindex and months I-I2 postindex; $* * N=9009 \mathrm{CB}, 9305$ controls months I3-I8 postindex; $N=6 \mid 28 \mathrm{CB}, \mathrm{N}=6203$ controls months $19-24$ post-index.

Abbreviations: ED/UC, emergency department/urgent care; IP, inpatient hospitalization; OP, outpatient visits.
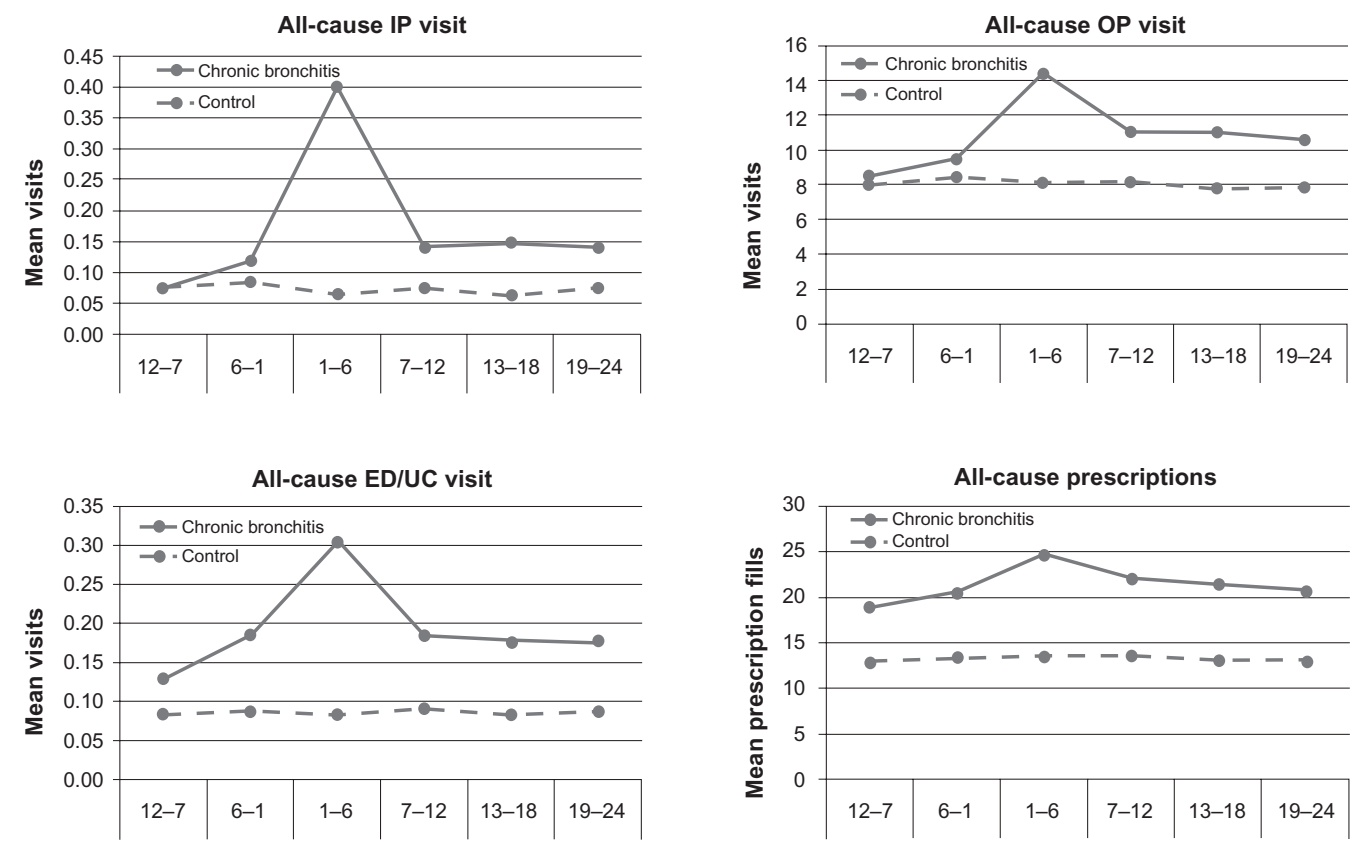

Figure 2 Mean events for chronic bronchitis and control populations.

Abbreviations: ED/UC, emergency department/urgent care; IP, inpatient hospitalization; OP, outpatient visits. 
Table 4 Mean costs (US\$) for chronic bronchitis and control populations

\begin{tabular}{|c|c|c|c|c|c|c|}
\hline & \multicolumn{2}{|c|}{ Preindex } & \multicolumn{4}{|c|}{ Postindex } \\
\hline & \multicolumn{2}{|c|}{ Months prior to index } & \multicolumn{4}{|c|}{ Months after index } \\
\hline & $7-12 *$ & $\mathrm{I}-6$ & $\mathrm{I}-6$ & $7-12$ & $13-18 * *$ & $19-24$ \\
\hline \multicolumn{7}{|l|}{ Total cost } \\
\hline Chronic bronchitis & $\$ 4,212$ & $\$ 5,289$ & $\$ 12,78 \mid$ & $\$ 7,101$ & $\$ 7,448$ & $\$ 6,925$ \\
\hline Control & $\$ 3,826$ & $\$ 4,285$ & $\$ 3,862$ & $\$ 4,070$ & $\$ 4,090$ & $\$ 4,496$ \\
\hline \multicolumn{7}{|l|}{ Medical services cost } \\
\hline Chronic bronchitis & $\$ 3,045$ & $\$ 4,034$ & $\$ 11,193$ & $\$ 5,562$ & $\$ 5,894$ & $\$ 5,415$ \\
\hline Control & $\$ 3,048$ & $\$ 3,438$ & $\$ 2,957$ & $\$ 3,152$ & $\$ 3,138$ & $\$ 3,520$ \\
\hline \multicolumn{7}{|l|}{ Pharmacy cost } \\
\hline Chronic bronchitis & $\$ 1,167$ & $\$ 1,255$ & $\$ 1,588$ & $\$ 1,539$ & $\$ 1,554$ & $\$ 1,510$ \\
\hline Control & $\$ 778$ & $\$ 847$ & $\$ 905$ & $\$ 917$ & $\$ 952$ & $\$ 976$ \\
\hline
\end{tabular}

Notes: All cost distributions were significantly different at a 0.05 level using Wilcoxon rank-sum test.

$* \mathrm{~N}=11674 \mathrm{CB}$ and controls months $12-1$ preindex and months I-12 postindex; $* * N=9009 \mathrm{CB}, 9305$ controls months $13-18$ postindex; $\mathrm{N}=6128 \mathrm{CB}, \mathrm{N}=6203$ controls months 19-24 postindex.

\section{Discussion}

This retrospective observational study demonstrated that total health care utilization and costs for CB patients in the US are significantly greater than for a matched control cohort of patients. This was true for both the 12-month period prior to $\mathrm{CB}$ diagnosis and for 2 years after diagnosis. Mean utilization and costs in the $\mathrm{CB}$ cohort were seen to increase in the 6 months immediately preceding diagnosis, a similar finding to that of Akazawa et al. ${ }^{17}$ This prediagnosis trend is commensurate with the gradual progression of COPD.
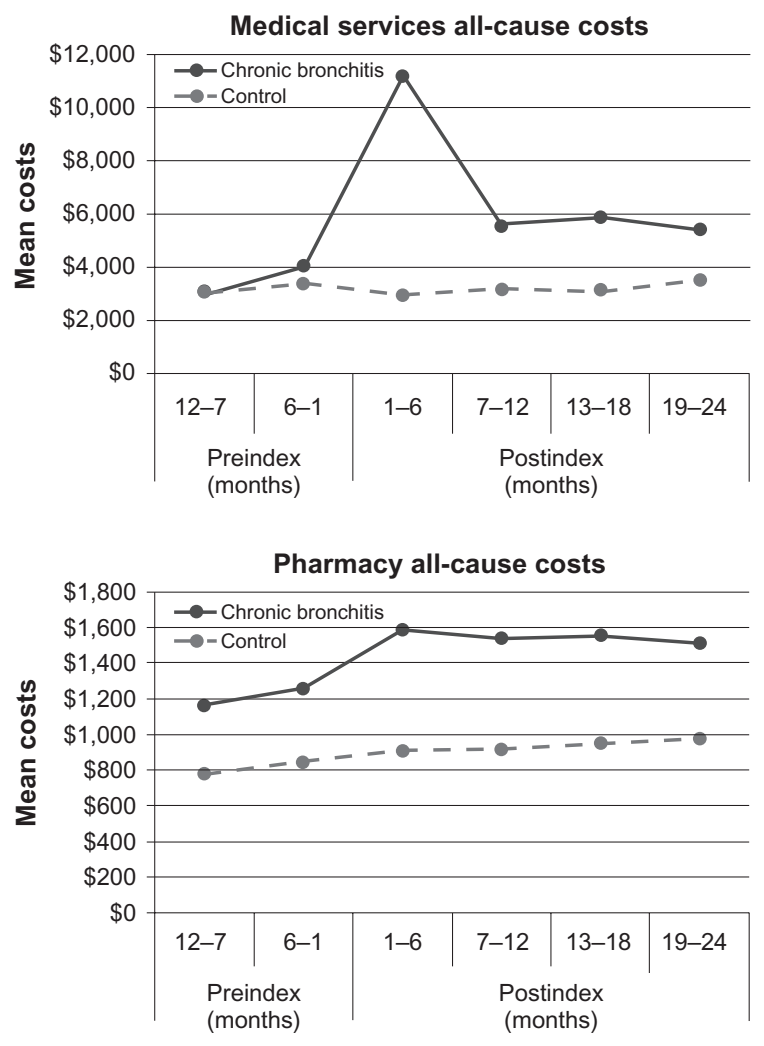

Figure 3 Mean costs (US\$) for chronic bronchitis and control populations.
In the postindex period, the majority of total health care cost differences between the cohorts were for medical services. Patients in the CB cohort incurred approximately US\$2000-\$2800 more for medical services across three of the 6-month postindex periods. During the same periods, the CB cohort's pharmacy costs were US $\$ 500-\$ 600$ higher than the control cohort. After the initial spike following a diagnosis of chronic bronchitis, medical services costs declined but remained elevated compared with controls, which may be due to increased utilization related to $\mathrm{CB}$ events, but also to non-CB related health events.

Prevalence of various comorbidities has been documented generally in studies of COPD patients, but there is a dearth of information concerning the extent to which comorbid conditions exist in patients with chronic bronchitis. Mapel et al found that in an analysis of a population in which $39 \%$ had cardiovascular disease and 13\% had diabetes, the presence of comorbid conditions was a better predictor of future costs of COPD patients compared with COPD disease stage as measured by spirometry. ${ }^{23}$ Similar prevalence rates of comorbidities have been found in other study populations. In a telephone survey of COPD patients, Barr et al found prevalence rates of more than $50 \%$ for hypertension and more than $25 \%$ for both depression and diabetes. ${ }^{24} \mathrm{~A} 2005$ review of 1090 Canadian patients with COPD levels ranging from asymptomatic to severe identified comorbidity rates of 51\% for hypertension, $19 \%$ for diabetes, $15 \%$ for depression, $13 \%$ for peripheral vascular disease, and $10 \%$ for asthma. ${ }^{25}$ Our CB cohort had a higher asthma rate compared with the COPD patients of the Canadian study, $23 \%$ versus $10 \%$, respectively; however, in a study of $\mathrm{CB}$ patients who were initiating maintenance therapy, Delea et al found an asthma comorbidity rate of $29 \%$, a prevalence rate similar to CB subjects in this analysis. ${ }^{26}$ 
Table 5 Median costs (US\$) for chronic bronchitis and control populations

\begin{tabular}{|c|c|c|c|c|c|c|}
\hline & \multicolumn{2}{|c|}{ Preindex } & \multicolumn{4}{|c|}{ Postindex } \\
\hline & \multicolumn{2}{|c|}{ Months prior to index } & \multicolumn{4}{|c|}{ Months after index } \\
\hline & $7-12 *$ & $1-6$ & $1-6$ & $7-12$ & $13-18 * *$ & $19-24$ \\
\hline \multicolumn{7}{|l|}{ Total cost } \\
\hline Chronic bronchitis & $\$ 1,559$ & $\$ 1,906$ & $\$ 4,007$ & $\$ 2,251$ & $\$ 2,261$ & $\$ 2,166$ \\
\hline Control & $\$ 1,163$ & $\$ 1,278$ & $\$ 1,252$ & $\$ 1,292$ & $\$ 1,215$ & $\$ 1,235$ \\
\hline \multicolumn{7}{|l|}{ Medical services cost } \\
\hline Chronic bronchitis & $\$ 591$ & $\$ 791$ & $\$ 2,364$ & $\$ 972$ & $\$ 1,008$ & $\$ 909$ \\
\hline Control & $\$ 534$ & $\$ 588$ & $\$ 563$ & $\$ 589$ & $\$ 550$ & $\$ 545$ \\
\hline \multicolumn{7}{|l|}{ Pharmacy cost } \\
\hline Chronic bronchitis & $\$ 581$ & $\$ 669$ & $\$ 911$ & $\$ 815$ & $\$ 796$ & $\$ 763$ \\
\hline Control & $\$ 347$ & $\$ 387$ & $\$ 396$ & $\$ 384$ & $\$ 367$ & $\$ 365$ \\
\hline
\end{tabular}

Notes: All cost distributions were significantly different at a 0.05 level using Wilcoxon rank-sum test.

$* N=11674 \mathrm{CB}$ and controls months I2-I preindex and months $\mathrm{I}-12$ postindex; $* * \mathrm{~N}=9009 \mathrm{CB}, 9305$ controls months $13-18$ postindex; $\mathrm{N}=6128 \mathrm{CB}, \mathrm{N}=6203$ controls months 19-24 postindex.

Similar to a study of COPD patients by Akazawa and colleagues, our study found higher IP, ED/UC, and pharmacy utilization in the 6 months prior to $\mathrm{CB}$ diagnosis; higher $\mathrm{ED} / \mathrm{UC}$ and pharmacy utilization was also observed even earlier, up to 1 year prediagnosis. The utilization differences became pronounced in the 6 months immediately preceding CB diagnosis, reached an apex during the next 6 months that included the index date (diagnosis), and then decreased. However, during the last three of the 6-month periods postindex, differences in mean medical services and pharmacy costs, as well as mean events, remained at levels of greater magnitude than those shown during both 6-month periods prior to $\mathrm{CB}$ diagnosis. This suggests that there is strong evidence that the systemic consequences of chronic bronchitis may play a significant role in driving up total health care utilization and costs among patients with chronic bronchitis.

A strength of our study is that we focused on adults aged 40 years and over, as opposed to an exclusively elderly population. An additional strength is that we examined health care utilization and costs in comparisons of $\mathrm{CB}$ and non- $\mathrm{CB}$ patients, whereas most of the literature has focused on the broader definition of COPD. A review by Maciewicz et al suggested that the varied aspects of the progression of COPD may be related to the aging process ${ }^{27}$ earlier disease identification and treatment initiation may improve patients' long-term health and economic outcomes, although the total cost savings may be modest due to shorter life expectancy for patients with COPD. ${ }^{28}$

This retrospective study based on claims data is not without limitations. Foremost among these is that the accuracy of diagnoses could not be verified. The results and conclusions of this study are limited to the population studied and the operational definitions of our variables. The analysis is limited to those with $\mathrm{CB}$ who utilize health care services and the representation of $\mathrm{CB}$ patients in the database we used of our analysis. The geographical representation in this study differed from what has previously been noted for the USA; that is, high prevalence in the South and Midwest. ${ }^{29}$ In addition, cost estimates may vary when different databases are used. Data were unavailable on both patient smoking behavior and severity of disease among the CB cohort, thus limiting our findings regarding drivers of resource utilization and cost.

\section{Conclusion}

To our knowledge, this is the first study to use a large enough population sample to facilitate propensity score matching based on comorbidities. Prior studies have not controlled for comorbidity by matching, ${ }^{30}$ creating potential for residual confounding and other biases in case-control comparisons. Our method allowed for a cleaner assessment of the true impact of $\mathrm{CB}$. The disease burden is greatest during the 6-month period following $\mathrm{CB}$ diagnosis, but is also high in periods preceding the diagnosis. In patients diagnosed with chronic bronchitis, compared with patients without evidence of COPD or asthma, health care utilization and costs continue to remain elevated 2 years after diagnosis. This study suggests that not accurately diagnosing $\mathrm{CB}$ early may have a substantial impact on health care costs, resulting in a higher economic burden for CB patients than would otherwise be present.

\section{Acknowledgment}

Financial support for this study was provided by GlaxoSmithKline (study \# ADC111268).

\section{Disclosure}

Dr Blanchette has received research support from and served as consultant to GlaxoSmithKline, AstraZeneca LP, Sepracor, Viostat, Wyeth, Schering-Plough, Premier, and 
NovoNordisk. Mrs Roberts has received research support from GlaxoSmithKline, AstraZeneca LP, Premier, and Wyeth. $\mathrm{Mr}$ Petersen has received research support from GlaxoSmithKline, AstraZeneca LP, Premier, and Wyeth. Dr Dalal is an employee of and owns stock in GlaxoSmithKline. Dr Mapel has received research support from and served as a consultant to GlaxoSmithKline, Pfizer Pharmaceuticals, BoehringerIngelheim Pharmaceuticals, and AstraZeneca. Susan R Berry, MSW, of Lovelace Respiratory Research Institute, was responsible for medical writing and editorial services for this manuscript. Ms Berry has no financial disclosures to report.

\section{References}

1. Niewoehner D. Structure-function relationships: the pathophysiology of airflow obstruction. In: Stockley R, Rennard S, Rabe K, Celli B, editors. Chronic Obstructive Pulmonary Disease. Malden, MA: Blackwell Publishing Ltd; 2007.

2. Pleis J, Lucas J, Ward B. Summary health statistics for US adults: National Health Interview Survey, 2008. Vital Health Stat. 2009; 10(242):1-167.

3. Wilson L, Devine E, So K. Direct medical care costs of chronic obstructive pulmonary disease: chronic bronchitis and emphysema. Respir Med. 2000;94(3):204-213.

4. Halpern M, Higashi M, Bakst A, Schmier J. The economic impact of acute exacerbations of chronic bronchitis in the United States and Canada: a literature review. J Manag Care Pharm. 2003;9(4):353-359.

5. Belfer M, Reardon J. Improving exercise tolerance and quality of life in patients with chronic obstructive pulmonary disease. JAm Osteopath Assoc. 2009;109(5):268-278.

6. Blanchette C, Broder M, Ory C, Chang E, Dalal A. Cost and utilization of COPD and asthma among insured adults in the US. Curr Med Res Opin. 2009;25(6):1385-1392.

7. Coventry P. Does pulmonary rehabilitation reduce anxiety and depression in chronic obstructive pulmonary disease? Curr Opin Pulm Med. 2009;15(2):143-149.

8. Habraken J, ter Riet G, Gore J, Greenstone M. Health-related quality of life in end-stage COPD and lung cancer patients. J Pain Symptom Manage. 2009;37(6):973-981.

9. Halpern M, Stanford R, Borker R. The burden ofCOPD in the USA: results from the Confronting COPD survey. Respir Med. 2003;97(Suppl C):S81-S89.

10. Hernandez P, Balter M, Bourbeau J, Hodder R. Living with chronic obstructive pulmonary disease: a survey of patients' knowledge and attitudes. Respir Med. 2009;103(7):1004-1012.

11. Izquierdo J, Barcina C, Jimenez J, Munoz M, Leal M. Study of the burden on patients with chronic obstructive pulmonary disease. Int $J$ Clin Pract. 2009;63(1):87-97.

12. Omachi T, Katz P, Yelin E, Gergorich S. Depression and health-related quality of life in chronic obstructive pulmonary disease. Am J Med. 2009;122(8):778-793.

13. Rodriguez Gonzalez-Moro J, de Lucas Ramos P, Izquierdo J, Lopez-Muniz Ballesteros B. Impact of COPD on physical disability and daily living activities: EDIP-EPOC I and EDIP-EPOC II studies. Int J Clin Pract. 2009;63(5):742-750.

International Journal of COPD

\section{Publish your work in this journal}

The International Journal of COPD is an international, peer-reviewed journal of therapeutics and pharmacology focusing on concise rapid reporting of clinical studies and reviews in COPD. Special focus is given to the pathophysiological processes underlying the disease, intervention programs, patient focused education, and self management protocols.
14. Global strategy for the diagnosis, management and prevention of chronic obstructive pulmonary disease. Global Initiative for Chronic Obstructive Lung Disease; 2009. www.goldcopd.com/Guidelineitem. asp?1=2\&2=1\&intId=2003. Accessed 2010 February 16.

15. American Lung Association. Understanding chronic bronchitis. 2010. Available from http://www.lungusa.org/lung-disease/bronchitischronic/understanding-chronic-bronchitis. Accessed 2010 Feb 16.

16. Tinkelman D, Price D, Nordyke R, Halbert R. Misdiagnosis of COPD and asthma in primary care patients 40 years of age and over. JAsthma. 2006;43(1):75-80.

17. Akazawa M, Halpern R, Riedel A, Stanford R, Dalal A, Blanchette C. Economic burden prior to COPD diagnosis: a matched case-control study in the United States Respir Med. 2008;102:1744-1752.

18. Mapel D, Robinson S, Dastani H, Shah H, Phillips A, Lydick E. The direct medical costs of undiagnosed chronic obstructive pulmonary disease. Value Health. 2008;11(4):628-636.

19. Mapel D, Robinson S, Lydick E. A comparison of health-care costs in patients with chronic pulmonary disease using lightweight portable oxygen systems versus traditional compressed-oxygen systems. Respir Care. 2008;53(9):1-7.

20. D'Agostino R Jr. Propensity score methods for bias reduction in the comparison of a treatment to a non-randomized control group. Statist Med. 1998;17(19):2265-2281.

21. Parsons L. Reducing bias in a propensity score matched-pair sample using Greedy Matching techniques. 26th Annual SAS User Group International Conference. 2001:214-226.

22. Elixhauser A, Steiner C, Harris D, Coffey R. Comorbidity measures for use with administrative data. Med Care. 1998;36(1):8-27.

23. Mapel D, McMillan G, Frost F, et al. Predicting the costs of managing patients with chronic obstructive pulmonary disease. Respir Med. 2005; 99(10):1325-1333.

24. Barr R, Celli B, Mannino D, Petty T. Comorbidities, patient knowledge, and disease management in a national sample of patients with COPD. Am J Med. 2009; 122(4):348-355.

25. Bourbeau J, Sebaldt R, Day A, Bouchard J, Kaplan A. Practice patterns in the management of chronic obstructive pulmonary disease in primary practice: the CAGE study. Can Respir J. 2008;15:13-19.

26. Delea T, Hagiwara M, Dalal A, Stanford R, Blanchette C. Healthcare use and costs in patients with chronic bronchitis initiating maintenance therapy with fluticasone/salmeterol versus other inhaled maintenance therapies. Curr Med Res Opin. 2009;25(1):1-13.

27. Maciewicz R, Warburton D, Rennard S. Can increased understanding of the rold of lung development and aging drive new advances in chronic obstructive pulmonary disease? Proc Am Thorac Soc. 2009; 6(7):614-617.

28. Joyce G, Keeler E, Shang B, Goldman D. The lifetime burden of chronic disease among the elderly. Health Aff (Millwood). 2005;24(Suppl 2): W5R18-W5R29.

29. American Lung Association. Trends in COPD (Chronic Bronchitis and Emphysema): Morbidity and Mortality. 2010. Available from: http:// www.lungusa.org/finding-cures/our-research/trend-reports/copd-trendreport.pdf. Accessed 2010 Nov 12.

30. Foster T, Miller J, Marton J, Caloyeras J, Russell M, Menzin J. Assessment of the economic burden of COPD in the US: a review and synthesis of the literature. COPD. 2006;3:211-218.

\section{Dovepress}

This journal is indexed on PubMed Central, MedLine and CAS. The manuscript management system is completely online and includes a very quick and fair peer-review system, which is all easy to use. Visit http://www.dovepress.com/testimonials.php to read real quotes from published authors. 